http://dx.doi.org/10.12795/PH.1992.v07.i01.08

\title{
EL DICTADOR LATINOAMERICANO (Aproximación a un arquetipo narrativo)
}

Francisca Noguerol Jiménez

The features that form the typical Latin-American dictator are outlined as they appear in the works belonging to the genre known as «dictator novel». It is also considered wether the portrait given by writers matches actual characters or it gives a softened image of their public and private life.

Los argentinos-dicen-nos dividimos en: aterrados, encerrados, enterrados y desterrados.

Eduardo Galeano: Días y noches de anor y de guerra ${ }^{1}$

Tengo en mis manos los cuatro ases: el de bastos, garrote de mi poder. El de oro en las arcas del Estado. El de copas en que darles de beber hiel y vinagre a los traidores. El de espadas para podarles la cabeza. Este es mi juego de truco. En él yo baso mi triunfo.

Augusto Roa Bastos: Yo el Supremo

Las citas de los escritores latinoamericanos Eduardo Galeano y Augusto Roa Bastos con las que abrimos nuestro artículo definen perfectamente los rasgos emblemáticos de la figura del dictador en la literatura iberoamericana.

2 A. Roa Bastos, Yo el Supremo (Buenos Aires 1975) 252. 
A lo largo de estas páginas se determinarán las características que configuran la figura del tirano latinoamericano, reiteradas en sus diferentes retratos de ficción y patentes en las obras englobadas dentro del metagénero literario denominado «novela del dictador».

Asimismo, plantearemos si la visión ofrecida por los diferentes escritores que se han ocupado de este personaje arquetípico se corresponde con la realidad o si por el contrario la creación literaria ofrece una imagen «suavizada» de los tiranos protagonistas y de sus acciones en la vida pública y privada.

En el prólogo que realizó Gabriel García Márquez para el libro de dibujos del escritor guatemalteco Arnoldo Ramírez Amaya titulado Sobre la libertad, el dictadory sus perros fieles $^{3}$ existe una interesante frase que resume el sentido último por el que los diferentes escritores emprendieron este tipo de narración. García Márquez nos aconseja pasar las páginas del libro de Ramírez y aprendernos de memoria la pesadilla totalitaria que refleja, pues según comenta el colombiano «con esta obra nos ha hecho el inmenso favor de ponernos en guardia contra el olvido» ${ }^{4}$.

El dictador no se origina como personaje específico de la literatura latinoamericana, pero al haberse consolidado como un lugar común de la realidad política de cualquier régimen transoceánico, se ha constituído en foco de atención permanente para los escritores de esta zona del mundo.

Desde la aparición de los primeros tiranos en la escena política iberoamericana encontramos «novelas del dictador» en el continente. Así, en 1851 se publica en Montevideo Amalia, de José Mármol, la primera obra incluída por derecho propio en el conjunto de tex tos que tratan el tema de la tiranía política, si bien la creación de Mármol contó con antecedentes tan importantes como el Facundo de Sarmiento o «El matadero» de Echeverría.

Sin embargo, sólo en el siglo XX el tirano se ha convertido en figura central de la literatura latinoamericana, configurándose sobre su base un modelo de personaje digno de ser estudiado en profundidad. Este hecho no es de extrañar, por cuanto la presente centuria se inicia con los regímenes políticos de Manuel Estrada Cabrera en Guatemala, de Porfirio Díaz en México y de Cipriano Castro en Venezuela entre otros.

A medida que pasan los años, aumentan las dictaduras: mientras Gerardo Machado y posteriormente Fulgencio Batista ejercen un poder omnímodo en Cuba, hacen lo propio Jorge Ubico en Guatemala; Hernández Martínez en el Salvador; Carías Andino en Honduras; Adolfo Díaz, Emiliano Chamorro, Juan B. Sacasa o la familia Somoza en Nicaragua; Juan Vicente Gómez y Pérez. Jiménez en Venezuela; Rojas Pinilla en Colombia; la familia Duvalier en Haití; Rafael Leónidas Trujillo en la República Dominicana; Sánchez Cerro y Odría en el Perú; González Videla en Chile; o, por citar a 
uno de los últimos déspotas derrocados, Stroessner (siguiendo los pasos de Higinio Moríñigo) en Paraguay.

Esta numerosa galería de tiranos reales ha motivado la constitución de un metagénero específico en el seno de la literatura hispanoamericana ${ }^{5}$.

El retrato literario del dictador se ha logrado a través de la descripción de los diferentes mecanismos utilizados por este para ascender al poder y permanecer posteriormente en él. Estos clementos, que constituyen su «ideología» política, acompañados de la descripción de sus vicios y virtudes, caprichos y veleidades, perfilan la silueta paradigmática del déspota en las novelas que comentamos.

Llegamos con ello al núclco de nuestro trabajo. Siguiendo el esquema ofrecido por Julio Calviño Iglesias en su obra La novela del dictador en Hispanoamérica ${ }^{6}$, podemos establecer los atributos que definen al déspota como ente de ficción.

Entre los rasgos que configuran la idiosincrasia del déspota (también llamado «Patriarca», «General», «Patrón», «Jefe» o «Padre de la Patria» en las diferentes obras) hacemos una división entre los rasgos que configuran su personalidad y los que determinan su actuación pública.

Las características emblemáticas de la personalidad del déspota se pueden sintetizar en los siguientes puntos: mesianismo, patrioterismo salvacionista, megalomanía, tanatofilia y misantropía.

Analizamos a continuación cada uno de ellos.

\section{Mesianismo}

La increíble vanidad de estos personajes se ve reflejada en su intención de codearse «de igual a igual» con Dios? ${ }^{7}$. Este hecho, que puede parecer hiperbólico y sólo posible en la ficción, viene refrendado por anécdotas reales que descubren el enorme narcisismo de los déspotas. Sirva de ejemplo el caso de Melgarejo, que escribía cartas a Dios recomendándole a sus víctimas, «dirigiéndose a El en los términos de querido primo, pues según el sátrapa, esta es la fórmula utilizada entre los jefes de Estado» ${ }^{8}$.

5 Hasta comienzos del siglo XX, la mayoría de las creaciones que conformaron «la novela del dictador» fueron sólo panfletos, virulentas diatribas con un valor artístico nulo o bastante escaso. Sin embargo, en los últimos años el conjunto se ha visto enriquecido por obras que tratan con rigor el tema del tirano latinoamericano y evidencian una gran calidad literaria. De hecho, algunos exponentes de la novela del dictador se encuentran entre las mejores narraciones creadas por autores latinoamericanos en el siglo XX (cf. Yo, el Supremo de Augusto Roa Bastos; El Recurso del Método, de Ali-jo Carpintifr; El Otoño del Patriarca, de García Márque\% o, finalmente, Oficio de Difuntos, de Usl.ar PitTri).

6. J. Cal viño) Itil.t.sias, La novela del dictudor en Hispanoamérica (Madrid 1985).

7 Así, en la obra del escritor Luis Ricardo) Ai.onso titulada El Supremísimo leemos que el dictador «en su intimidad solía IIamar a Dios el Ser Vicesupremo" (Barcelona 1984, 204).

* Citado por C. Zui.onga, Novelas del dictador, dictadores de novela (Bogotá 1979), 120. 


\section{PATRIOTERISMO SALVACIONISTA}

El dictador se considera imprescindible para la buena marcha de la nación. Sólo él está capacitado para tomar decisiones, por insignificantes que estas sean. Sus ínfulas salvacionistas se hacen patentes en la figura del doctor Francia, sátrapa paraguayo a quien su biógrafo Julio César Chaves atribuye las siguientes palabras:

Todo esto por hallarme en un país de pura gente idiota, donde el gobierno no tiene a quien volver los ojos, siendo preciso que yo lo haga, lo industrie, y lo amaestre, todo por sacar al Paraguay de la infelicidad y abatimiento en que ha estado sumido por tres siglos".

El dictador Francia fue el modelo en el que se inspiró Augusto Roa Bastos para escribir su famoso alegato contra la dictadura titulado Yo el Supremo, y así el personaje de ficción repite las palabras del tirano real en la novela:

Además de Dictador Perpetuo debo ser al mismo tiempo Ministro de Guardia, Comandante en Jefe, Supremo Juez, Auditor Militar Supremo, Director de la Fábrica de Armamento. Suprimidos los grados oficiales superiores hasta el de capitán, yo solo constituyo la Plana Mayor completa de todas las armas. Director de Obras Públicas, debo vigilar personalmente hasta el último artesano, la última costurerilla, el último albañil, el último peón caminero ${ }^{10}$.

\section{Megalomanía}

Si en la ficción el personaje de El Supremísimo creado por Luis Ricardo Alonso exclama: «Sé que me tienes envidia Napoleón no lo niegues»" , la figura real de Rafael Leónidas Trujillo, primer general con cinco estrellas en el mundo, que rigió los destinos de la República Dominicana por espacio de treinta y un años, supera con creces este rasgo de egocentrismo. Su grotesca vanidad lo llevó a imponerse a sí mismo -entre otros-los títulos que detallamos a continuación, recogidos por Hans Magnus Enzensberger en su obra Política y delito :

El Benefactor de la Patria, el Honorable Presidente, El Paladín de la Democracia, El Primer Médico de la República, el Portador de la Gran Cruz de la Orden Papal de San Gregorio, el Supremo Coloso, El Genio de la Paz, El Salvador de la Patria, El Protector de todos los Obreros, el Caballero de Honor de la Soberana Orden de Malta, el Primer Maestro de la República, el Padre de la Nueva Patria, el primero y el más grande de todos los Jefes de Estado dominicanos, el Héroe del Trabajo, el Primer Periodista de la República, el Generalísimo de las Fuerzas Armadas, el 
portador del Collar de la Orden de Isabel La Católica y otras ochenta y siete altísimas distinciones ${ }^{12}$.

Este gobernante de visos kafkianos redondeó su actuación política imponiendo a las calles de la capital (por entonces denominada Ciudad Trujillo) los nombres de su padre, madre, esposa e hijos, erigiendo bustos de su persona en número superior a mil ochocientos y diseminando por toda la república placas como la que colocó en un terraplén construído cerca de Santo Domingo y en donde se leía: «Trujillo, hacedor de esta tierra» ${ }^{13}$.

El colmo de la megalomanía viene expresado humorísticamente por el protagonista de la novela de Luis Ricardo Alonso El Suprenlísimo, que en una ocasión comenta: «Todos los Gaudísimos somos ninfomaníacos del poder» ${ }^{14}$.

\section{TANATOFILIA}

«Fusilo, luego existo», comenta «el Supremísimo» de Alonso ${ }^{15}$. Esta frase es ya suficientemente significativa de la atracción que siente el tirano iberoamericano hacia la muerte como su más efectivo instrumento de poder, atracción que se hace aún más patente al leer el rosario de monstruosidades practicadas por los dictadores reales y de las que Conrado Zuloaga ofrece una síntesis en su obra Novelas del dictador, dictadores de novela:

Mientras que Hernández Martínez asesina 10.000 campesinos acusándolos de comunistas, Justo Rufino Barrios hace de su sicario una tea humana; Tiburcio Carías acaba con sus opositores hasta la tercera generación; Trujillo secuestra, en Estados Unidos, a escritores y los hace desaparecer para siempre; Somoza asesina a traición al líder revolucionario Sandino; Juan Vicente Gómez confina en las prisiones a sus enemigos, que mueren devorados por los mismos gusanos que generan sus llagas al estar atados a grillos de más de cien kilos; (...) Ubico se deleita con las fotografías de los torturados y en la República Dominicana existen fosos de tiburones y perros adiestrados para castrar ${ }^{16}$.

De este modo, no puede extrañarnos encontrar frecuentes descripciones de un subido naturalismo -lindante con el feísmo- en las novelas del dictador, entre las que citamos como ejemplo el siguiente fragmento de gran crudeza, incluído en Las Varonesas de Carlos Catania:

La mamá del Pollo, dos hermanitos y el perro, colgaban de las patas clavados los tacos en las vigas, como conejos. A ella la habían abierto en dos, previas incursiones donde ya

H. M. Enzensbergrer, Política y delito (Barcelona 1968) 36.

Estas anécdotas son narradas por C(oNRAIx) Zui.)AGa en op. cit, 29-30.

L. R. AJ.onso, op. cit, 150.

Ibíd, 193.

16. C. ZuI onacia, op. cit., 120. 
se sabe. El enemigo no conocía entonces la picana y otros chunches delicados del ingenio argentino. Olvídese también de Pinochet y sus técnicas ${ }^{17}$.

\section{MisAntropía}

El desprecio generalizado hacia quienes le rodean lleva al déspota a ser un individuo eminentemente solitario. Si existe algún clemento que suscite la compasión del receptor en la lectura de estas obras, este viene dado por la soledad, que pesa como un baldón insoportable en la existencia de estos hombres. Del doctor Francia comenta su biógrafo Chaves: «Su existir está lleno de soledad; nadie se mueve en su círculo: ni amantes, ni parientes, ni amigos. A nadie se liga, a nadie escucha, a nadie quiere» ${ }^{18}$. También «El Supremo» medita en la novela de Roa Bastos sobre su aislamiento, al recordar una caída de caballo que lo llevó a vagar por sus dominios durante la noche:

[La tormenta de agosto] me volteó del caballo la tarde del último paseo. En medio de la lluvia, tumbado de espaldas, pugné desesperadamente por zafarme de la succión del barro. (...) Al fin pude incorporarme pesado de barro y desesperanza. Vagué toda la noche por la ciudad, apoyado en una rama cogida al azar. No me atreví a merodear las proximidades de la Casa de Gobierno por temor a mis propios guardianes (...) Vagabundo, El Supremo Mendigo, el Unico Gran Limosnero. Solo. Llevando a cuestas mi desierta persona. Solo, sin familia, sin hogar, en país extraño. Solo. Nacido viejo, sintiendo que no podía morir más. Condenado a desvivir hasta el último suspiro. Solo. Sin familia. Solo, viejo, enfermo, sin familia, sin siquiera un perro a quien volver los ojos ${ }^{14}$.

En cuanto a las características predominantes en la actuación pública del dictador destacaremos las siguientes: retoricismo vacuo, intereses nacionales hipotecados al imperialismo foráneo, apoyo en una oligarquía caciquista, fomento del mito, nepotismo y liberticidio.

\section{RETORICISMO VACUO}

Si existe un rasgo externo que identifique a los dictadores de novela este es el de su común afectación a la hora de elaborar discursos, por los que sienten verdadera devoción. Podemos percibir este retoricismo vacuo en el siguiente párrafo de la novela de Alejo Carpentier El recurso del método:

\footnotetext{
17 C. Catania, Las Varomesas (Barcelona 1978), 129.

is J. C. Chaves, op. cil, 206.

19) A. RoA Bastos, op. cit, 422.
} 
Acallados los vítores, cl Presidente, arrancando en tiempo lento, marcando las pausas, como era su costumbre, empezó a pronunciar un discurso bien articulado,,.. , aunque se adornaba demasiado - este era el parecer de muchos- de expresiones tales como «trashumante», «mirobolante», «rocambolesco», «erístico», «apodáctico», antes de que, subido de tono en una relumbrante movilización de horcas caudinas, espadas de Damocles, pasos de Rubicón, trompetas de Jericó, Cyranos, Tartarines y Clavileños, revueltos con altivas palmeras, señeros cóndores y onicrótales alcatraces, se diese a increpar a los «jenízaros del nepotismo», a los «miméticos demagogos», a los «condotieros de alfeñique»... ${ }^{20}$.

Este hecho se pone asimismo de manifiesto en la novela de Demetrio Aguilera Malta El secuestro del general, comentándose lo siguiente acerca del dictador que en este caso posee el significativo nombre de Holofernes Verbofilia:

Tal vez lo único que no podría soportar sería que le impidiesen pronunciar discursos. Eso representaría el mayor castigo que pudieran infligirle (...) Sin discursos, no podría seguir viviendo ${ }^{21}$.

INTERESES NACIONALES HIPOTECADOS AL IMPERIALISMO FORÁNEO

Si existe una figura imprescindible en las novelas del dictador desde los comienzos de nuestra centuria, esta es la del agregado militar norteamericano, que aconseja y orienta al tirano en sus campañas contra los «rebeldes», consiguiendo como contrapartida grandes ventajas económicas. Así, en El Recurso del Método el embajador norteamericano, retratado cómicamente «con camiseta de la Universidad de Yale y cara de puritano viejo», se permite ofrecer al Primer Magistrado «una rápida intervención de tropas norteamericanas para salvaguardar las instituciones democráticas $»^{22}$, argumentando que «precisamente, unos acorazados estaban por entonces de maniobras por el Caribe» ${ }^{2.3}$. Aunque en un principio el Magistrado no cede a la presión de los que califica como «gringos de mierda» ${ }^{24}$, temiendo una intromisión estadounidense en los asuntos internos del país, al final debe ceder para «aunar» sus fuerzas con las de América del Norte, nación que colaborará posteriormente a su derrocamiento de forma decisiva, cuando ya no le conviene mantenerlo en el poder. Y es que como señala Eduardo Frei, personaje de la novela de Fernando Alegría El paso de los gansos, «Revolución se escribe con dólares $»^{25}$.

Del mismo modo, el Patriarca de García Márquez llega al poder bajo la protección del comandante Kitchener y con el beneplácito del cónsul británico, soportando durante su mandato el asedio de los embajadores Palmerston, Warren, Wilson, Maryland, Rumpel-

\footnotetext{
20 A. Carplintitr, El Recurso de Método (México 1974), 47-48.

21 D. Aguilera Malta, El secuestro del general, (México 1973), 88.

22 A. Carpentier, op. cit, 72.

$2, \quad$ Ibíd.

24 Ibíd.

25 F. Al.t:GRÍA, El paso de los gansos (Barcelona 1980), 164.
} 
mayer, Traxler, Baxter, Streimberg, Roxbury y una larga caterva de observadores estadounidenses que lo llevan finalmente a vender el mar de sus dominios a un tal Ewing ${ }^{26}$.

Si el mayor error del Patriarca ficticio consistió en vender el mar, en la realidad este hecho simbólico se vio superado por las actuaciones de Trujillo, Somoza, Batista, Machado, Ubico, Adolfo Díaz o Juan Vicente Gómez, quienes practicaron una política de absoluta sumisión a los intereses del imperialismo norteamericano.

FOMENTO DEL MITO

Uno de los rasgos emblemáticos de la figura del tirano viene dado por la entidad mítica que cobra este frente al pueblo. En Yo El Supremo leemos algunos ejemplos del resultado obtenido en la encuesta que el dictador ha encargado realizar en las escuelas con el fin de controlar la educación:

Alumna Liberta Patricia Núñez, 12 años: «El Supremo Dictador tiene mil años como Dios y lleva zapatos con hebillas de oro bordadas y ribeteadas con piel. El Supremo decide cuándo debemos nacer y que todos los que mueran vayamos al cielo, de modo que allí se junta mucha gente» (...) Alumno Prudencio Salazar Espinosa, 8 años: «El Supremo Gobierno tiene 106 años. Nos ayuda a ser buenos y trabaja mucho haciendo crecer el pasto, las flores, las plantas. (...) Alumna Genuaria Alderete, 6 años: «El Supremo Gobierno es como el agua que hierve fuera de la olla, que siempre está hirviendo aunque se apague el fuego, y hace que no nos falte la comida». (...) Alumno Amancio Recalde, 9 años: «Pasa a caballo sin mirarnos pero nos ve a todos y nadie lo ve a El» ${ }^{27}$.

\section{NEPOTISMO}

El nepotismo de que hacen gala los tiranos se revela como una constante histórica reflejada en una gran cantidad de novelas del dictador.

Como ejemplo histórico de este trato de favor dispensado a los parientes, citamos el siguiente fragmento de la obra de William Krehm Democracia y tiranias en el Caribe:

Por lo que toca al ilustre latinista González Víquez [dictador costarricense], fue más paternal que fraternal: destinó un yerno al Ministerio de la Guerra, y un sobrino a la gobernación. El presidente León Cortés nombró a su hermano administrador del Ferrocarril del Pacífico, propiedad del estado, a su cuñado Ministro del Interior, y convirtió a su hijo Otto en presidente del Congreso, mientras el segundo era desplazado como Cónsul 
General a Nueva York. El presidente Rafael Angel Calderón Guardia nombró a su padre Primer Designado, y a su hermano Francisco, Ministro del Interior.... ${ }^{28}$.

El ejemplo más escandaloso de los extremos a los que puede llegar el favoritismo presidencial lo ofrece Rafael Leónidas Trujillo, quien «colocó» a sus diez hermanos del modo que sigue: casó a sus cuatro hermanas, respectivamente, con un Mayor del Ejército, un General que al mismo tiempo hacía las veces de senador, un diputado, y un señor desconocido que de la noche a la mañana consiguió el monopolio en el negocio de la Lotería. En cuanto a los varones, fueron en su orden:

Traficante en armas, y Ministro en París; dueño del Monopolio de Exportación frutera y del monopolio de la carne; cobrador de los impuestos a la prostitución; Mayor de la Guardia Nacional; General de la Guardia Nacional; jefe del ejército y presidente de la república cuando Trujillo quiso permanecer entre bastidores ${ }^{29}$.

Ofrecemos un fragmento de la novela escrita por Alejo Carpentier El recurso del Método, en la que se retrata perfectamente la vida que suelen llevar los hijos de los dictadores latinoamericanos:

Ofelia [su hija y confidente, a quien consulta todos sus asuntos] era quien era (...),y, siendo como era, seguiría igual, en genio y figura, a la niña arrebatada, empeñosa, a la vez tenaz e inestable, que había sido... De Ariel no tenía quejas: fue parido para diplomático [de hecho, este vástago del Primer Magistrado ocupa significativamente el cargo de Embajador en Washington]... Con Radamés, la desdicha, entre muchos éxitos, había sido tan dura como tajante... en una carrera automovilística de Indianápolis, voló al cielo, sobre el asfalto caliente de la sexta milla... ${ }^{30}$.

En El otoño del Patriarca, el texto de García Márquez incluído en el conjunto de los que integran el metagénero de la novela del dictador, existe un episodio que puede catalogarse como el colmo de esta actitud de favor a los parientes reflejada en la literatura. Así, el Patriarca, llevado de su devoción hacia Bendición Alvarado, su rústica madre, entabla una guerra particular con el Vaticano para canonizar a su progenitora, teniendo que conformarse por último con proclamar la «santidad civil» de esta:

[El Patriarca] proclamó la santidad civil de Bendición Alvarado. Por decisión suprema del pueblo libre y soberano la nombró patrona de la nación, curadora de los enfermos y maestra de los pájaros y se declaró día de fiesta nacional el de la fecha de su nacimiento ${ }^{31}$.

Este hecho podría ser considerado irreal y sólo posible dentro de los límites de la literatura si no supiéramos que Trujillo hizo del día de cumpleaños de su madre una fiesta patria, llegando a canonizarla civilmente -junto con su hija- aun cuando estas vivían.

\footnotetext{
28 W. Krht: Democracia y tiranias en el Caribe (Buenos Aires 1967), 202-203.

29 C. ZuloAgA: Novelas del dictador, dictadores de novela, op. cit, 75.

30 A. CARPENTIER, El recurso del Método, op. cit, 68.

3 En El otoño del Patriarca, op. cit, 160.
} 


\section{LIBERTICIDIO}

La supresión de cualquier oposición al régimen instaurado constituye una de las bazas principales sobre las que se asientan los sistemas dictatoriales.

Esta resistencia se manifiesta, tanto en la historia como en la literatura, en tres frentes principales, constituídos por los activistas que se lanzan a la lucha de forma suicida y desorganizada, por la prensa y por los estudiantes, respectivamente.

El mejor representante de los insurrectos que luchan sin estrategias claras pero con arrojo contra la tiranía nos lo ofrece Valle Inclán en el personaje de Zacarías San José también llamado Zacarías el Cruzado, el único agente de Tirano Banderas que no es víctima de una cruel sátira por parte del escritor gallego. Este hombre, a quien le han devorado el hijo «los chanchos en la ciénaga» ${ }^{32}$, cultiva su rencor contra Santos Bandera hasta convertirse en una fuerza incontenible. Así, exclama ante su amigo Filomeno Cuevas:

Con solamente otro compañero dispuesto, revoluciono la feria; vuelco la barraca de las fieras y abro las jaulas. ¿QQué dice el patrón? ¿No se armaría la buena? Con cinco valientes pongo fuego a todos los abarrotes gachupines. Con veinticinco copo la guardia de los Monteses ${ }^{33}$.

En cuanto al denominado «cuarto poder», la prensa, ejerce un importante papel ante la opinión pública mundial, por cuanto difunde en los círculos internacionales los crímenes cometidos por el régimen.

Es el caso de «la prensa parisina» que, en El recurso del Método, endilga al Primer Magistrado el sobrenombre de «El Carnicero de Córdoba» en un reportaje sobre las campañas militares que este ha llevado a cabo contra los insurrectos.

Del mismo modo, en el seno de cada nación existen imprentas clandestinas. A pesar de la persecución que sufren por parte del tirano, los volantes subversivos que salen de sus rulos ayudan decisivamente a minar el poder desde sus cimientos. Los editoriales de estos periódicos ilegales llegan incluso a la bandeja del desayuno del Primer Magistrado en El recurso del Método:

[En ellas] no se le insultaba ya a la criolla, en jerga de solar y conventillo, con retruécanos y chistes de fácil invención, como antes se hacía, sino que, definiéndosele como Dictador (más le hería esta palabra que cualquier epíteto soez, cualquier intraducible remoquete, porque era moneda de enojoso curso en el extranjero -y sobre todo en Francia- se revelaban al público, con lenguaje escueto y tajante, muchas cosas -actos, negocios, decisiones, eliminaciones...- que jamás hubiesen debido llegar al conocimiento de las gentes... ${ }^{34}$

\footnotetext{
12 R. M. DH: VAIII InCl.ÁN, Tirano Banderas (Madrid: Aguilar, 1971), 354.

13 R. M. DEI. VAILF. INCI.ÁN, op. cit, ibid.

3 A. CARPEnTIFR, op. cit, 185.
} 
La otra cara de la moneda la ofrece la prensa oficial, encargada de mantener la imagen del tirano, que si en la narración de Carpentier confiere al Presidente los títulos de «Pacificador» $\mathrm{y}$ «Benemérito de la Patria» ${ }^{35}$, en la realidad llegó a los extremos de alabar la gestión económica de Jorge Ubico o de señalar en una ocasión, durante la dictadura de «el brujo de los Andes», que «El General había conseguido cambiar el clima de la ciudad de Maracay» ${ }^{36}$.

En cuanto al estudiante, constituye el principal elemento desestabilizador de cualquier régimen tiránico, presente en la mayoría de las novelas del dictador. Así, en El señor Presidente de Miguel Angel Asturias el joven intelectual -que aun encerrado en el calabozo mantiene sus ideales-representa la última esperanza de salvación para el pueblo, cuando todas las ilusiones se han perdido bajo el gobierno del terror. Del mismo modo, el estudiante es el responsable de casi todos los actos contra el orden en El recurso del método: no sólo organiza la huelga que acaba con el omnímodo poder del primer mandatario, sino que edita el periódico clandestino y maquina todos los «atentados» frustrados de los que ha sido víctima la suprema autoridad del país.

\section{APOYO EN UNA OLIGARQUía GAMONALISTA}

Pasamos a destacar el trato de favor que el dictador dispensa a su equipo de trabajo, a quien ya Valle Inclán denominó agudamente «la trinca de compadritos» ${ }^{37}$.

En el irónico y desmitificador texto de Manuel Mújica Lainez titulado De milagros y melancolías existe un excelente retrato de quienes rodean al tirano. En una ocasión, este los obliga en señal de vasallaje y pleitesía a maullar en coro, lo que cumplen al instante dando lugar a una cómica escena, en la que «los delegados de la aristocracia maullaban con la elegancia de los gatos persas; los enviados de los batuques, con la fiereza de los gatos onzas» ${ }^{38}$.

Si en El recurso del Método el delfín del Primer Magistrado aparece personificado por la figura del doctor Peralta, que acompaña al Presidente a los burdeles con un maletín no cargado de documentos oficiales - como pregona ante todos- sino de botellas de ron ${ }^{39}$, el séquito del Patriarca creado por García Márquez está compuesto por su guardaespaldas,

is Ibíd., 137.

16 Así se lee en el Reader's Digest y El Universal de Caracas, respectivamente. Hemos tomado esta noticia de C. Zuloaga, op. cit, 106.

17 En Tirano Banderas se nos ofrece uno de los mejores retratos de la camarilla de favoritos cuando se la retrata riendo las «gracias» del dictador, «asustada, complaciente y ramplona» (Tirano Banderas, op. cit, 522). Del mismo modo, en su relato «Las fieras del trópico», el guatemalteco Rafael Arévalo refleja la bestialidad y simpleza de los «ministros» y «militares» en el poder haciendo uso de la técnica de comparación zoomórfica y transformándolos en diversos animales -toro, oso, buey...- ante los ojos del lector («Las fieras del trópico», en El señor Monitot, Guatemala 1922, 58).

is M. Música Lain::, De Milagros y melancolías (Buenos Aires 1969), 263.

3) A. CARPENTII:R, op. cit., 18. 
un hombre violento y bestial; su doble; su sicario personal, creador de la cámara de torturas; y finalmente «el compadre de toda la vida», el ministro de defensa, que acaba sus días siendo asado a fuego lento y servido en la mesa al resto de los miembros del estado mayor, cuando el tirano descubre su traición:

Y cuando hubo en cada plato una ración igual de ministro de defensa con relleno de piñones e hierbas de olor, él dio la orden de empezar, buen provecho señores ${ }^{40}$.

La figura del «general felón», el que maquina en la oscuridad la traición contra su benefactor de toda la vida, aparece reflejada en casi todas las novelas del dictador. Si en Tirano Banderas recibe el nombre de coronel Domiciano de la Gándara, en El otoño del Patriarca será el finalmente devorado Rodrigo de Aguilar, a quien ya hemos hecho referencia, y en El recurso del Método asumirán este rol los generales Ataúlfo Galván y Walter Hoffman. La mejor descripción de estos delfines insurrectos la tenemos en la última novela citada, en un fragmento donde el Primer Magistrado se queja en medio de imprecaciones de la traición de que ha sido objeto:

-!Coño de madre! !Hijo de puta! -repetía el Primer Magistrado, como si a estas únicas palabras se hubiese limitado su vocabulario, al pensar en la felonía de quien había sacado de la mugre de un cuartel provincia, chácharo de mierda, sorche de segunda, amparándolo, enriqueciéndolo, enseñándole a usar el tenedor, a halar la cadena del retrete, y que ahora se aprovechaba de su ausencia para... El hombre que, tantas veces, en las recepciones de Palacio; muy metido en copas, lo hubiese llamado benefactor, providencia, más que padre, compadre, padrino de mis hijos, carne de mi carne, se le alzaba así a la boliviana... ${ }^{41}$.

Concluímos en este punto nuestro repaso de las características que configuran la figura del dictador relacionadas con la actuación pública de este. En este breve estudio, hemos escogido entre el rosario de obras que constituyen el metagénero de la narrativa del Poder Personal algunos textos que poseen una incuestionable calidad artística y que no se quedan en la violenta diatriba contra el régimen tiránico. Este hecho no impide que en todos ellos la literatura se entienda como una transgresión al poder instituído, y que a cada uno de ellos se le pueda aplicar las palabras que Jorge Enrique Adoum, en su novela Entre Marx y una mujer desnuda, dirigía al escritor comprometido, y con las que finalizamos nuestra comunicación:

Para justificarte recuerdas que frente a la barbarie y la estupidez zoológica encaramadas en el techo del Poder, un libro también puede ser un acto subversivo ${ }^{42}$.

4i) G. García MárquY:L, op. cit, 127.

4 A. CARPI:NTIF, op, cit, 31.

42 J. Enriqua: Adoum, Entre Marx y una mujer desnuda, (México 1976), 81. 